\title{
1. An academic career: initiating the journey
}

\author{
Tomislav Hernaus and Matej Černe
}

Estimated reading time: 19 minutes and 35 seconds.

\section{CHAPTER HIGHLIGHTS}

- Academia, with all its appeals related to pursuing your passions in an autonomous manner, represents a risky career journey that a very few manage to master successfully.

- Each scholar can and should develop his or her own modus operandi, a unique way of practicing scholarship that will eventually be effective within his or her specific academic environment.

- Higher education trends and ongoing reshaping of academic work impose a lot of imperatives for scholars, particularly young(er) ones.

- In this volume, instead of speaking about the average or universal scholar, we put upfront an idea of a different or authentic scholar.

- Our intention is to promote prosocial behavior, rejuvenate academic citizenship and give a new boost to academic discovery.

A journey of a thousand miles begins with a single step.

Lao Tzu

\section{SCHOLAR(SHIP) AT THE CROSSROADS}

A first step, whether made by a child or an apprentice, is characterized by a great human desire and is mostly driven by positive expectations. French people like to say: "Quand on veut, on peut [When we want, we can]!" However, we should not disregard a great amount of uncertainty present in decision-making, usually stemming from missing self-confidence, lack of knowledge and/or from not having experience. Both our goals and circumstances create the risk we have to take to prosper. Without taking the initiative 
in our lives, things will not happen by themselves, certainly not in a way we would like them to.

The world of academia is not so different from everyday life. Actually, it represents the real world to numerous scholars worldwide. Some of them are well-established university professors and research scientists with long and successful careers, others are young scholars or doctoral candidates that strive to enter and leave their mark within the field. While the former generally have secure job positions and already established routine practices, the latter are still trying to find their place under the sun. Most of them are aware of a very broad range of opportunities offered by academia, but they might struggle with a significant number of academic pitfalls and dead ends that could pop up along the way. Seductive as it is, academia represents a risky career journey that a very few manage to master successfully. It easily drags you in and shows you the beauty of the skies, but when you want to do something heavenly, it is anything but easy. Someone who has not tried it cannot know it.

Making a career in academia is not simple or predictable. Often you will be left on your own to make very important decisions. There will be no one to ask, or nothing to read about a particular topic of interest. You will not be able to find a solution easily or receive necessary advice about your research, primarily because there are no easy answers, or you are supposed to create one. However, besides being creative and producing a new science, an academic career is also strongly determined by the capability of handling ourselves and organizing our academic activities. Working within a knowledge-intensive occupation that provides you with a high level of autonomy, each scholar can and should develop his or her own modus operandi, a unique way of practicing scholarship that will eventually be effective within his or her specific academic environment.

Being original or even artistic in a sense is not easy, especially not today when scholarship is a hard game to play. Higher education trends and ongoing reshaping of academic work impose a lot of imperatives for scholars, particularly young(er) ones. The decline of budget funding and the emergence of "academic capitalism" (Slaughter \& Leslie, 1997), together with increased competition and further globalization of the academic profession, have been detrimental to academic work in many respects during recent years (Ylijoki, 2005). Not only do (younger) faculty nowadays need to do "more" than their (experienced) forerunners in terms of teaching or research, but they also have uncertain promotion possibilities, circumscribed employment appointments, and are required to fulfill "inhuman" expectations placed by tenure committees. Obviously, the faculty work is changing - the research requirements, a teaching load, administrative and service demands, the diversity of appointments, the necessary skills and abilities (Austin \& Wulff, 2004). 
Aforementioned external threats make scholarly beginnings even harder to handle effectively. The increasing pressure on junior faculty to publish more and achieve distinction in their discipline (Schuster \& Finkelstein, 2006) often leads to a burnout and makes professoriate a less attractive workplace. Those who manage to survive largely depict their work in very negative terms: "killing", "chaotic", "overloaded", "conflicting", "mad", and "disappointing" (Ylijoki, 2005). While some authors (e.g., Arnowitz, 2001, in Kalleberg, 2011) believe that the job of a university professor is becoming precarious, we are convinced that it is still "the best job in the world". You just need to know how to make "the right" moves.

\section{THE ACADEMIC VALUE OF SHARING AND COLLABORATION}

A common truth is that no person knows everything. Neither did Aristotle, Leonardo da Vinci, or Alexander von Humboldt. While they were undoubtedly the most knowledgeable people during their times, and have greatly entrusted our civilization with their knowledge, nowadays a highly-educated individual on average probably has more information than they had. The logic is clear - "if we want to see further, we need to stand on the shoulders of giants" (Newton, 1675, in Turnbull, 1959).

The same is applicable to reaching the master level in the academic profession. The need to better understand the faculty was explicitly recognized by 1942 when Logan Wilson published The Academic Man in an effort to systematize what was known of these professionals responsible for higher education (Schuster \& Finkelstein, 2006). Since then, a traditional academic value of sharing has resulted in several very good and thought-provoking books of essays published about the academic life (for example, Andre \& Frost, 1997; Deneef \& Goodwin, 2007; Frost \& Taylor, 1996; Hällgren, 2014). They are certainly a must-read literature for upcoming generations of scholars. Written by world-leading and well-accepted scholars, reflective essays offer deep insights into different aspects of the academic world. The notable knowledge base and long-career experience accumulated by hardened authors, translated into hints and advice, represent "a vitamin food" for each junior, and even for a large number of mid- and senior-career stage scholars.

However, we believe that things are not any more as they were. The world of academia is in constant flux, the academic work is adaptive and revolutionary, and the traditional understanding of the role of the professional academic has been strongly challenged (Fleck \& Hess, 2014). The criteria of being a successful scholar, as well as pathways of becoming one are much different than 30-40 years ago. It is not that "the old school" professors no longer have legitimacy; yet senior scholars "need to stop setting a bad example" (see 
Harley, 2019) in a world where traditional academic values are in conflict with processes of rationalization in business schools and universities. We thus entertain the possibility that young(er) scholars and academic apprentices could also hear something and learn a bit from the personal observations of their somewhat more experienced yet still mid-career colleagues.

This book is not intended to be yet another publication manual or a writing guide for doctoral students. It is not an academic survival handbook either. The aim of the book is to qualitatively analyze individuals' idiosyncratic lived experiences of academic careers. We do not want to be over-troubled with university and scholarly ratings, journal impact factors, citation rates, and similar quantitative bibliometric measures. While these numbers are definitely shaping perceptions of academic success and will be mentioned to a certain extent throughout the book, our intention is to apply a narrative approach. Instead of speaking about the average or universal scholar, we would like to put upfront an idea of a different or authentic scholar.

Each of us (volume contributors) is a differentia specifica. We have different goals, different backgrounds, different experiences, different skills and abilities, different work environments. On the other hand, we are not so very different at all. We definitely struggle with the same work challenges, study somewhat related organizational topics, and probably mostly share similar academic values. We are thoroughly immersed in our discipline and academic work. Our differences and similarities go hand in hand. By providing common ground that is supplemented with various flavors, we are looking forward to presenting readers with a well-informed, puzzling view of academic landscapes. This book does not aim to move the frontiers (i.e. to be a critical text) within the sociology of science, but its intention is to share personal stories about academic survival and scientific outreach.

\section{THE MEMBERS OF THE CREW}

Diversity is a mother of invention. However, too much diversity could be problematic. Thus, what we really need and expect for most of the time is a controlled diversity. This book certainly provides a diversity of success. A group of younger, mid-career researchers and still predominantly junior professors decided to share their thoughts, beliefs and gimmicks about how they do academic business - something that earlier sociological studies of science rarely focused on (Prpić, 2000). They offer a wide range of experience and expertise. Nevertheless, the diversifying academic profession (Teichler, 2010) and the paradigm of different academic worlds (Clark, 1987) led us to narrow the focus and to resonate our stories within the field of organization studies a discipline that we are familiar with. 
Our orchestra consists of the internationally composed group of younger scholars $^{1}$ who have already made a difference within academia. Even though historical analyses show that major scientific discoveries are the contribution of young people (Kuhn, 1962; Lehman, 1953; Musselin, 2007), by no means have we wanted to narcissistically think about ourselves as some kind of übermensch (superman or superwoman). Excellence among faculty members is certainly not unidimensional. The criteria of academic excellence have often been a topic of dispute. What really makes a great scholar is still non-consensual because it is almost impossible to find the dynamic equilibrium that will completely cover the diversity of academic work.

Subsequently, it should be clear that the choice of contributors for this volume was subjective. As editors, we decided to invite colleagues by profession, some of them whom we did not even know, but whose achievements were notable and admirable. Each author is a "high quality" scholar, in oversimplified terms, a person of exceptional competence and dedication to his or her academic tasks (Schuster \& Finkelstein, 2006). The chosen ones are aspiring scholars (something that is evident from their curricula vitae [CVs]) who were brave enough to speak openly about and share their values and motives, positive and negative emotions, passions and fears, and first academic successes and failures. These 15 brave male and female musketeers decided yet again to take a risk and expose themselves in order to give. Certainly there are plenty more prolific scholars who would be interested to share their thoughts and do have something to say, but unfortunately the number of seats was limited.

The volume contributors' ages range between 32 and 47, with an average age of $40 .^{2}$ They represent an international group of scholars with different countries of origin (Austria, Belgium, Brazil, Croatia, Finland, Germany, Greece, Serbia, Slovenia, Sweden, United States) who mainly have assistant or associate professorship positions. Their academic experience ${ }^{3}$ has been gained across 17 different European and North and South American countries (see Figure 1.1 for more details) and within 31 higher education institutions (for example, Boston University, Case Western Reserve University, IE Business School, Indiana University, INSEAD, London School of Economics, Nova School of Business and Economics, Royal Institute of Technology, Stanford University, Technical University of Munich, University of Edinburgh, University of Nebraska-Lincoln, University of Notre Dame, University of Toronto, Warwick Business School, WU Vienna, and others).

Each contributor is an independent and aspiring researcher with a respectable early-career track-record. In total, volume contributors have already published 48 books, 185 book chapters, 581 Web of Science (WoS) publications, some of which are in top-tier academic journals (Academy of Management Journal, Journal of Management, Strategic Management Journal, Human Resource Management, The Leadership Quarterly, Human 


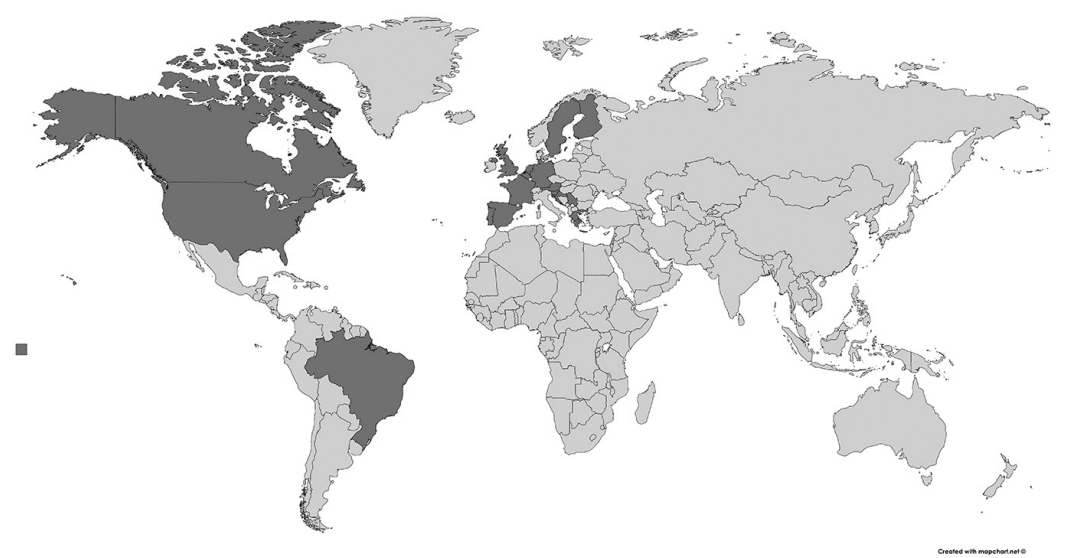

Note: Created with mapchart.net. The dark areas represent contributors' academic experience.

Figure 1.1 World map of contributors' academic experience

Resource Management Journal, Human Relations, Organization Science, Journal of Business Venturing, Journal of Applied Psychology, Journal of Organizational Behavior, Harvard Business Review, Organizational Behavior and Human Decision Processes, Project Management Journal, Journal of Business Research, and others). Their work has been largely cited (15 352 WoS citations and 54643 Google Scholar citations on 16 November 2020), ${ }^{4}$ and they have won numerous prestigious awards (e.g. $\mathrm{PhD}$ thesis awards, best paper awards, junior/emerging researcher awards, extraordinary teaching awards). Having a place on the journal editorial boards (Academy of Management Journal, Academy of Management Discoveries, Human Resource Management Journal, Human Resource Management Review, The Leadership Quarterly, Journal of Applied Psychology, Journal of Management Studies, Journal of Business Venturing, Organization Studies, Journal of Occupational and Organizational Psychology, European Management Journal) or playing important roles in professional associations (Academy of Management, European Academy of Management), as well as being visiting professors (for instance, Stanford University, UCLA, Aarhus University, HEC Montreal, University of Pennsylvania), grant holders and research project managers, they have confirmed their potential, passion, and responsibility for academic work. The contributing authors have been carefully chosen to cover working practices from different angles and perspectives. Thus, we believe the academic plate will be more presentable. 


\section{TO WHOM IT MAY CONCERN}

The world of academia is a very crowded place in which to live and work. It is larger than you have probably ever imagined. In 2001 the National Center for Education Statistics counted about 1.11 million faculty members across the United States (Schuster \& Finkelstein, 2006). Similar statistical data unfortunately do not exist at the global level, but we could assume there are certainly more than five million scholars worldwide. Although our autobiographical essays might be interesting to the whole academic population, we are modest enough not to think out loud that it could become an academic bestseller.

This volume is primarily targeted at doctoral candidates and early-career researchers. According to Meri (2007), just in Europe there are approximately 680000 doctoral candidates (Ates et al., 2011). Similar numbers are applicable for the United States. That is a lot of young and ambitious people to write for. We were driven by Bailey's (1997) reflection that "reading about others struggling with similar issues, experiencing the highs and lows of the learning process, trying the same or similar kinds or techniques, and expressing the same kinds of values can be heartening". Something similar did not exist during our academic beginnings, so we wanted to make the academic life more understandable to newcomers.

The approaches and techniques explained throughout the book might inspire and help young scholars to become respectful members of the professoriate. Academic respectfulness should not be maintained through workaholism or by becoming the "hyper-productive publication machine". We do not support a ruthless "publish or perish" philosophy. In our view, the end does not justify the means. Higher university or department ratings are something very nice to have and to be proud of, but they do not represent a goal in itself. Instead of being constantly under pressure, exhausted and exploited, young scholars should have the opportunity to enjoy their scholarship. They need to find a work-life balance and the meaning of their work, because only in such circumstances can they contribute to their society.

We do hope that our specific writing style and personal reflections will have a positive effect on a potential cohort of readers. Our intention is to promote prosocial behavior, rejuvenate academic citizenship and give a new boost to academic discovery. As some might think, we do not have hidden self-promotion intentions. Instead, we would like to give what we have learnt from our experiences. Translated into the words of Harvard political scientist Robert Putnam: "We'll do this for you without expecting anything specific back from you, in the confident expectation that someone else will do something for us down the road" (Grant, 2013). Only such a way of reasoning can move us further afield towards a better and happier society. 


\section{DIE SPEISEKARTE OR THE BOOK MENU}

The book is structured into six parts each approaching an academic career from a different perspective: (I) as preparing for a voyage; (II) as a journey; (III) through career transitions; (IV) as an act of balancing and role switching; (V) an arena to practice your personal style; and (VI) looking to the future and seizing the horizon. In total, we present three overviews and 15 autobiographical chapters.

To begin with and to prepare for the voyage, it is important to be clear about the full range and scope of work activities that most academics engage in. Therefore, Tomislav Hernaus and Matej Černe have written a chapter about academic work design. They address a four-legged stool approach that needs to ensure the balance among a diverse set of academic (i.e. research, teaching, service) and personal activities (i.e. family matters, growth and development).

The next three chapters describe an academic career as a unique journey. Eleanna Galanaki starts the adventure by comparing her academic career to Homer's epic poem, Odyssey. Career challenges, risks, and pitfalls, as well as rewards, opportunities, and benefits experienced in modern Greek academia are discussed in the light of the Ancient Greek text. She attempts to find analogies and antitheses between the original epos and the odyssey of her academic life. Hana Milanov continues by describing her unexpected country-hopping academic career path that took her from Croatia, through the United States and Spain, to Germany. In her chapter, she discusses similarities and differences between academic expectations, daily life, and work-life balance across countries and cultures. Amy Van Looy concludes this part of the book by putting upfront the idea of practice-oriented research. Specifically, her prior consultancy expertise and ongoing business practice experience strongly influence her academic behavior and performance, representing an inexhaustible source of research topics to pursue.

Academic career transition challenges, both approached from the historical and futuristic perspective, are well addressed in the following three chapters. Jelena Zikic describes herself as being a career nomad. Most of her career decision-making (i.e. international journey, migration, and work-family decisions) followed her career instinct, which certainly played a role at career intersections. Being a career researcher, she authoritatively talks about the benefits of continuous career reflection and reinvention. Matej Černe thoroughly explains the change in roles and responsibilities that accompany his career shifts triggered by several life-changing events. He builds the case of reaching a successful academic career by turning fortune into favor through practicing hard work, proactive behavior and being persistent. Karoline Strauss explores how our future work selves are shaped, questioned, abandoned, and reinvented 
throughout our academic careers, and how, despite a changing landscape in academia, they may provide a sense of purpose and direction. In a similar vein, she embraces the impact that each of us could have on others' future work selves as we advance into senior positions.

Academic balancing and role switching is certainly a challenge for the majority of contemporary academics. Therefore, we have included four chapters addressing this topic specifically. Ante Glavaš recounts how he followed a non-traditional path and eventually moved from being a corporate person to an academic position seeker. He reveals how his academic life was influenced by a single top-tier publication, and explains how it is still challenging to find meaning in the different roles that an academic plays. Tomislav Hernaus puts upfront the notion of constant struggle for survival between various types of academic activities. He recommends that junior scholars pay attention to the academic balance dynamics already present at the beginning of their journey by sticking to their personal philosophy, having sources of inspiration and support, and building ethics of responsibility. Alf Rehn discusses the many roles of the modern academic, and the manner in which this multitude establishes borders and border-crossings that challenge stable professional identities. His autobiographical case enquires into both the pitfalls and the positive aspects of switching between seemingly paradoxical positions, and suggests ways in which academics can overcome their anguish over playing multimodal roles. Sonja Rispens writes about the prevalence of collaborative relationships and conflicts that academic researchers face. Based on both personal experiences and scientific research, she clarifies the value of collaboration and the same time describes the different types of conflicts we as academics may encounter while collaborating with other researchers.

Finally, the most extensive part of the book covers five chapters describing personal styles within academia. Indeed, each scholar experiences his or her own personal odyssey that might eventually be more or less successful. To increase the odds of the success, Kristina Potočnik takes the reader through her academic career, particularly highlighting the importance of serendipity and resilience for completing a $\mathrm{PhD}$ and persisting in academic circles. Drawing on self-experience, she presents a realistic picture of the often-mystified academic life by discussing some of the key challenges that an early-career researcher is likely to face. Joana Story uses the dance metaphor to present different career perspectives and personal experiences. Each dancing style introduced (fado, samba, capoeira, and choro) represents different career stage for which key success factors (or "dance lessons") for effective research have been offered. Jan Mendling explicates his case of growing up as an academic by emphasizing research collaborations as a great way of learning. From his standpoint, scientific teamwork represents the key factor of publication productivity, especially if you have a chance to collaborate with inspirational persons. Markus 
Hällgren explores the opportunities to establish a research career by purposefully doing things differently. His chapter provides insights into the principles, tools, and methods that were used, and have continued to be used by the author in order to find and keep the passion alive. Last, but not least, Spencer Harrison takes a highly creative approach of reflecting upon academic work by asking what our children think about how we spend our time. His personal experiment yields some interesting insights on sacrifices we are expected to take while pursuing a productive and enriching academic career. Contributors' main messages to the new generation of scholars are concisely presented and briefly commented on by the editors in the ultimate chapter of this volume.

\section{A BRIEF NOTE ON METHODS APPLIED TO EASE READABILITY}

Unless you are an experienced academic, reading scholarly work is not always straightforward. This may be so because we (academics) mostly do not start writing from scratch; instead, we assume that readers are well enough informed about the topic to get engaged in the discussion at a certain level of understanding. Being aware of the problem, we (editors) have applied several "tricks" in order to make this volume more attractive to a wider (non-informed) audience. Specifically, what you can find useful to get motivated to read subsequent pages is as follows:

- Chapters follow a narrative approach to reflect on personal odysseys with a basic level of theorizing.

- Contributors were given freedom to craft their chapters as they prefer (content and substance, writing style, with or without referencing ${ }^{5}$ ), which ultimately resulted in a very disparate set of relevant academic career themes.

- The chapter length has been standardized (8 000 word count limit).

- Each contributor has received constructive editorial feedback from the perspective of an uninformed reader.

- Five key chapter takeaways have been recognized and highlighted by editors.

- An estimated reading time ${ }^{6}$ is provided for each chapter.

Preparing this volume has involved much introspection and a search for reasons for the causes of our behaviors and approach to academic life. It shows "many roads that could be taken in an academic career" (Mello, 1997). Beyond literally opening the academic horizon, we also wanted to spread the idea about positive organizational scholarship and dare to hope that our book is maybe 
one such example. Eventually, we are not afraid to admit that we are hooked on being academics! Maybe you will feel the same after you read the book.

\section{NOTES}

1. Different ways of classifying faculty cohorts exist. For instance, according to Schuster and Finkelstein (2006), new entrants are faculty in the first seven years of full-time teaching, mid-career faculty are those who have between eight and 14 years of full-time teaching experience, and senior faculty have 15 or more years of full-time teaching experience. A more widespread approach is to see young researchers as those who have reached the age of 35 years or less (Prpić, 2000). Ates at al. (2011), under the term junior researcher, refer to all young researchers who have finished their doctorate and are working at the postdoctoral level within the academic/research sector. Within the United States, age level criteria seems to be somewhat higher, as they have the award "Top young professors under 40". Despite age differences, ranks of full professor and associate professor are considered to be senior academics, and assistant professor and lecturer ranks are usually considered to be junior academics (Aarrevaara \& Dobson, 2013).

2. Although it should be noted that we were somewhat younger when the book project was initiated and the chapters had been written.

3. Here defined as previous and current work experience, scholarship visits longer than three months as well as formal enrollment in master of science or doctoral programs.

4. While these numbers are impressive, we should be fair and give a special credit to our "superstar" Jan Mendling who by himself has 5600 WoS and 24791 Google Scholar citations.

5. Most contributors decided to retain academic rigor and have cited other scholarly work to evidence and strengthen their argument. In total, 381 reference sources have been used in this volume.

6. We decided to follow a global trend (e.g., Amazon Kindle, McKinsey Digital, The Economist App) and recommended examples (e.g., Bailey, 2016; Messner \& Wänke, 2011) to introduce an estimated reading time for each chapter. The Read-O-Meter online calculator has been used to calculate this time based on the 200 words per minute reading average.

\section{REFERENCES}

Aarrevaara, T., \& Dobson, I. R. (2013). Movers and shakers: Do academics control their own work? In U. Teichler, \& E. A. Hohle (eds.), The Work Situation of the Academic Profession in Europe: Findings of a Survey in Twelve Countries (pp. 159-181). Dordrecht: Springer.

Andre, R., \& Frost, P. J. (eds.). (1997). Researchers Hooked on Teaching: Noted Scholars Discuss the Synergies of Teaching and Research. Thousand Oaks, CA: Sage Publications.

Ates, G., Hollander, K., Koltcheva, N., Krstić, S., \& Parada, F. (2011). Eurodoc Survey I: The First Eurodoc Survey on Doctoral Candidates in Twelve European Countries. Brussels: Eurodoc - The European Council of Doctoral Candidates and Junior Researchers. 
Austin, A. E., \& Wulff, D. H. (2004). The challenge to prepare the next generation of faculty. In D. H. Wulff, A. E. Austin et al. (eds.), Paths to the Professoriate: Strategies for Enriching the Preparation of Future Faculty (pp. 3-16). San Francisco, CA: Jossey-Bass.

Bailey, C. (2016). The Productivity Project: Proven Ways to Become More Awesome. London, UK: Piatkus.

Bailey, D. (1997). The power of dialogue: Celebrating the praxis of teaching and research. In R. Andre, \& P. J. Frost (eds.), Researchers Hooked on Teaching: Noted Scholars Discuss the Synergies of Teaching and Research (pp. 301-312). Thousand Oaks, CA: Sage Publications.

Clark, B. R. (1987). The Academic Life: Small Worlds, Different Worlds. Lawrenceville, NJ: Princeton University Press.

Deneef, A. L., \& Goodwin, C. D. (eds.). (2007). The Academic's Handbook. Durham, NC: Duke University Press.

Fleck, C., \& Hess, A. (2014). Introduction: Public sociology in the making. In C. Fleck, \& A. Hess (eds.), Knowledge for Whom? Public Sociology in the Making (pp. 1-15). Farnham, UK: Ashgate.

Frost, P. J., \& Taylor, M. S. (eds.). (1996). Rhythms of Academic Life: Personal Accounts of Careers in Academia. Thousand Oaks, CA: Sage Publications.

Grant, A. M. (2013). Give and Take: A Revolutionary Approach to Success. New York, NY: Viking.

Hällgren, M. (ed.). (2014). Reflections on a Scientific Career - Behind the professor's CV. Stockholm/Copenhagen: Liber/Copenhagen Business Press.

Harley, B. (2019). Confronting the crisis of confidence in management studies: Why senior scholars need to stop setting a bad example. Academy of Management Learning \& Education, 18(2), 286-297.

Kalleberg, A. L. (2011). Good Jobs, Bad Jobs: The Rise of Polarized and Precarious Employment Systems in the United States, 1970s to 2000s. New York, NY: Russell Sage Foundation.

Kuhn, T. S. (1962). The Structure of Scientific Revolutions. Chicago, IL: University of Chicago Press.

Lehman, H. C. (1953). Age and Achievement. Princeton, NJ: Princeton University Press.

Mello, J. (1997). Teaching in the real world. In R. Andre, \& P. J. Frost (eds.), Researchers Hooked on Teaching: Noted Scholars Discuss the Synergies of Teaching and Research (pp. 178-196). Thousand Oaks, CA: Sage Publications.

Meri, T. (2007). Doctorate holders. The beginning of their career. Statistics in Focus, Science and Technology, 131, 1-8.

Messner, C., \& Wänke, M. (2011). Unconscious information processing reduces information overload and increases product satisfaction. Journal of Consumer Psychology, 21(1), 9-13.

Musselin, C. (2007). Transformation of academic work: Facts and analysis. In M. Kogan, \& U. Teichler (eds.), Key Challenges to the Academic Profession (pp. 175-190). Kassel: UNESCO Forum on Higher Education.

Prpić, K. (2000). The publication productivity of young scientists: An empirical study. Scientometrics, 49(3), 453-490.

Schuster, J. H., \& Finkelstein, M. J. (2006). The American Faculty: The Restructuring of Academic Work and Careers. Baltimore, MD: Johns Hopkins University Press.

Slaughter, S., \& Leslie, L. (1997). Academic Capitalism: Politics, Policies and the Entrepreneurial University. Baltimore, MD: Johns Hopkins University Press. 
Teichler, U. (2010). The diversifying academic profession? European Review, 18(1), $157-179$.

Turnbull, H. W. (ed.). (1959). The Correspondence of Isaac Newton: Volume 1 (1661-1675). Cambridge, UK: Cambridge University Press.

Ylijoki, O.-H. (2005). Academic nostalgia: A narrative approach to academic work. Human Relations, 58(5), 555-576. 